\title{
Robotic management of congenital urethra-vaginal fistula with transverse vaginal septum
}

\author{
Shanti Laxmi Darga ${ }^{1}$, Mallikarjuna Chiruvella ${ }^{1}$, Taif Mohammed Bedigeri ${ }^{1}$, Ghouse Syed Mohammed \\ ${ }^{1}$, Sarika Pandya ${ }^{1}$, Bhavatej Enganti ${ }^{1}$ \\ ${ }^{1}$ Department of Urology, Asian Institute of Nephrology \& Urology, Hyderabad, India
}

\section{ABSTRACT}

Introduction: The transverse vaginal septum (TVS) with congenital urethra-vaginal fistula (CUVF) is a rare anomaly of the mullerian duct $(1,2)$. Incomplete channelling of the vaginal plate, or an abnormality in the fusion of the vaginal component of mullerian duct with the urogenital sinus results in TVS $(1,3,4)$. High CUVF occurs due to the persistent communication between the urogenital sinus and utero-vaginal primordium at the tubercle sinus, whereas low CUVF is due to excessive apoptosis of the vaginal plate during channelling (5). The principles of management of CUVF with TVS include: 1) TVS resection, 2) Create a neovagina. We present a case of CUVF with TVS managed by robotic assistance. Material and methods: A 24-year-old female, married for 3 years, presented with cyclical hematuria since menarche, dyspareunia and primary infertility. Examination revealed blind ending vagina $4 \mathrm{~cm}$ from the introitus. Magnetic resonance imaging revealed a fistulous communication between urethra and vagina, and TVS. Cystourethroscopy confirmed a proximal urethra-vaginal fistula. Urethroscopy guided puncture of the TVS was performed, tract dilated and a catheter was placed across it. Robotic assisted transvaginal approach was planned. Air docking of robot was performed. Traction on the catheter was given to identify the incised edges of the septum. Vaginal flaps were raised laterally, fistulous tract was excised. Proximal vagina mucosa was identified and vaginoplasty was performed.

Result: Patient's postoperative recovery was uneventful. Urethral catheter was removed after 5 days. She had normal voiding and menstruation. Vaginoscopy performed at 1st month follow-up, revealed an adequate vaginal lumen. Vaginal moulds were advised for 6 weeks during the night, following which she resumed her sexual activity. She conceived 6 months post-surgery, and delivered a child by caesarean section.

Conclusion: We successfully managed this case by resection of septum, neovagina creation and thereby achieving normal menstruation and conception. The advantages of robotic approach were magnification, precision and manoeuvrability in a limited space, avoiding a vaginal release incision.

\section{CONFLICT OF INTEREST}

None declared. 


\section{REFERENCES}

1. Amer MI, Ahmed Mel-S, Ali AH. Congenital urethrovaginal fistula with transverse vaginal septum. J Obstet Gynaecol Res. 2016; 42:1042-5.

2. Dhabalia JV, Nelivigi GG, Satia MN, Kakkattil S, Kumar V. Congenital urethrovaginal fistula with imperforate hymen: a first case report. J Obstet Gynaecol Can. 2009; 31:652-3.

3. Kamal EM, Lakhdar A, Baidada A. Management of a transverse vaginal septum complicated with hematocolpos in an adolescent girl: Case report. Int J Surg Case Rep. 2020; 77:748-52.
4. Moegni F, Quzwain S, Rustamadji P. Transverse vaginal septum managed by simple flap surgery technique: A case report. Int J Surg Case Rep. 2021; 83:105990.

5. Koichi Ohno, Tatsuo Nakaoka, Yuichi Takama, Atsushi Higashio, Kenji Santo, Akihiro Yoneda. Congenital urethrovaginal fistula associated with imperforate hymen causing fetal urinary ascites and abdominal cystic lesions: A case report and literature review. Journal of Pediatric Surgery Case Reports 2015, 3, 48-52.
Submitted for publication:

May 29, 2021

Accepted after revision:

June 15, 2021

Published as Ahead of Print:

September 10, 2021

\section{Correspondence address:} Darga Shanti Laxmi, MD Department of Urology, Asian Institute of Nephrology \&t Urology, 6-3-562/A, behind more megastore, Erramanzil colony Hyderabad, 500082, India, Telephone: +91 40 6731-3131 E-mail: shantidarga@gmail.com

\section{ARTICLE INFO}

Shanti Laxmi Darga

https://orcid.org/0000-0003-2715-263X

Available at: http://www.intbrazjurol.com.br/video-section/20210421_Laxmi_et_al

Int Braz J Urol. 2022; 48 (Video \#2): 198-9 